\title{
Slow infections
}

\section{Spongiform virus encephalopathies}

\author{
D. CARLETON GAJDUSEK
}

From the National Institutes of Health, Bethesda, Maryland, USA

Two subacute degenerative diseases of the central nervous system of man (Gajdusek and Gibbs, 1971), kuru and Creutzfeldt-Jakob disease, and two of animals, scrapie in sheep and goats and mink encephalopathy, are strangely atypical infections caused by highly unconventional viruses (Gajdusek and Gibbs, 1972). These four diseases have very similar neuropathology with a similar basic cellular lesion, namely, of clearing of neuronal cytoplasm and formation of vacuoles in pre- and postsynaptic terminals and eventual neuronal destruction with the production of a status spongiosus of grey matter (Lampert, Earle, Gibbs, and Gajdusek, 1969 and 1970; Lampert, Hooks, Gibbs, and Gajdusek, 1971). There is an associated astroglial hypertrophy and hyperplasia, and the astrocytes seem to be actually stimulated in culture in vitro as they are in vivo.

The four diseases are caused by filterable viruses with strange physical and biological properties; they have an exceptionally long incubation period of many months or years, and a characteristic, unremitting, always fatal, progressive course. The physical properties of the agents have been determined far more extensively for the two animal viruses than for the two agents of the human diseases, in which expensive laboratory primates have been the only susceptible species to date. However, the physical characteristics of the human agents already studied seem to place them, as do their pathogenesis and their other biological properties, together with scrapie and mink encephalopathy, in a unique group of unusual agents, new to microbiology.

The infections are atypical in a further respect. They elicit no inflammatory response in the brain where they cause pathology nor in other organs in which the viruses may be present but no pathology is evoked (Beck, Daniel, and Gajdusek, 1966; Beck, Daniel, Gajdusek, and Gibbs, 1969 and 1970). In all other virus infections of the brain there is a reaction of perivascular cuffing with mononuclear cells; mononuclear cell inflammatory invasion of the parenchyma and meningeal and ependymal involve- ment are common. In these atypical infections, the cerebrospinal fluid shows no pleocytosis nor any rise in protein throughout the course of infection. The patient remains afebrile.

Thus, these diseases differ from other slow infections of the human brain which have subsequently been demonstrated: delayed and slow measles encephalitis or subacute sclelosing panencephalitis (SSPE) (Baublis and Payne, 1968; Horta-Barbosa, Fuccillo, London, Jabbour, Zeman, and Sever, 1969); subacute papovavirus encephalopathy activated by immunosuppression, natural or iatrogenic, as progressive multifocal leucoencephalopathy (PML) (ZuRhein and Chou, 1968; Gardner, Field, Coleman, and Hulme, 1971; Padgett, Walker, ZuRhein, Eckroade, and Dessel, 1971; Weiner, Herndon, Narayan, and Johnson, 1972a; Weiner, Herndon, Narayan, Johnson, Shah, Rubinstein, Preziosi, and Conley, 1972b; epilepsia partialis continua or Kozhevnikov's epilepsy caused by the RSSE virus in the Soviet Union (and in an experimental system in rhesus monkeys) (Asher, 1971); progressive congenital rubella and cytomengalovirus brain infections; and subacute encephalitides with herpes simplex virus or with adenovirus type 32 (Roos, Chon, Rogers, Basnight, and Gadjusek, 1972). In all of these infections virus-like inflammatory responses occur in the brain.

Most noteworthy of the properties of kuru- and scrapie-like agents has been their failure to elicit any antibody response in naturally or experimentally infected animals, or to elicit any antibody response in a wide variety of hosts inoculated repeatedly with suspensions containing the agents in high infectivity titre, with and without the use of adjuvants. Neutralization tests and tests in vitro, such as complement fixation and radioactive immunoprecipitation, and attempts to demonstrate fluorescent antibody using sera from infected animals and from animals passively immunized have all been negative. Thus, to date, no antigenic properties of the agents have been found.

All four agents have been propagated in vitro in 
cell cultures derived from the brains of infected animals (Gajdusek, Gibbs, Rogers, Basnight, and Hooks, 1972; Gustafson and Kanitz, 1965; Haig and Clarke, 1971; Marsh and Hanson, 1969), but no transmission of the agents in such silent carrier states to other cell lines has yet been demonstrated. There is no cytopathic effect in these still-virulent cell cultures, and for scrapie and mink encephalopathy, at least, active replication of the agents in such carrier cultures has been proved (Gustafson and Kanitz, 1965; Haig and Clarke, 1971; Marsh and Hanson 1969). As mentioned above, the glial cells from infected animals seem to be stimulated in such cultures (Caspary and Bell, 1971).

There has been controversy as to the physicochemical nature of the viruses of this group (Adams, 1970; Hunter, 1970; Alper, 1972; Diener, 1972a and b. Almost all work on these agents has been done using crude tissue suspensions, and in all attempts to purify them the infectivity is regularly associated with fragments of membrane (Kimberlin, Millson, and Hunter, 1971; Gajdusek and Gibbs, unpublished data). Electron microscopy of affected tissues has failed to reveal any recognizable packaged virions (Lampert, 1969 and 1970; Lampert et al, 1971). Tissue suspensions of high infectivity or pellets of sedimented infectivity do not contain a visible virus-like particle (Gajdusek and Gibbs, unpublished data). Yet, wherever virus infectivity is high, as in specific density gradient bands, there the electron microscope reveals only fragments of membranes (Gajdusek and Gibbs, unpublished data). Similarly, in the characteristic, even pathognomonic lesions of these agents in the brain, the intraneuronal vacuoles are not empty, but filled with a debris of packed sheets and curled fragments of membrane (Lampert et al, 1969, 1970; Lampert et al, 1971), the same membrane as that which forms the wall of the vacuoles and which is familiar to all virologists as the surface membrane of those viruses formed by budding from the cell or into cell vacuoles.

The enormous resistance of these transmissible agents to heat inactivation and to exposure to several agents which rapidly inactivate most viruses, such as proteolytic enzymes, acetylethylenamine, formaldehyde, and RNase and DNase and, particularly their extreme resistance to ultraviolet inactivation (Haig, Clarke, Blum, and Alper, 1969; Latarjet, Muel, Haig, Clarke, and Alper, 1970), has led to speculation that they are infectious agents lacking any nucleic acid for their replication. Several possible structures of selfreplicating macramolecules not containing nucleic acids have been postulated by various authors (Adams, 1970; Hunter, 1970) including proteins, basic proteins, and polysaccharides. The inactivation of scrapie by membrane-disrupting substances (ether, periodate, urea, phenol) has led to the hypothesis that it may be a replicating membrane or a membraneassociated polysaccharide alone (Gibbons and Hunter, 1967; Millson, Hunter, and Kimberlin, 1971). We know this about its structure: it is closely associated with membranes and inactivated when such association is broken, it is probably not usually packaged into morphologically recognizable virions, and it lies in the size range of 25 to $35 \mathrm{~nm}$. Filtration studies on kuru to date have failed to pass the agent through membranes of $100 \mathrm{~nm}$ minimal pore diameter, and this is in sharp contrast to the easy passage of scrapie and mink encephalopathy through such membranes. The UV-inactivation data (Haig et $a l, 1969$; Latarjet et al, 1970) would suggest that no nucleic acid is present, but what level of repair or of protection from UV-inactivation may be associated with firm binding of small nucleic acids to membranes is still an unknown matter. When one further allows for the possibility of very small size, as the RNA of potato spindle tuber virus, chrysanthemum stunt virus, and citrus exocortis virus with RNA genomes of under 50000 daltons, we do not really know what physical inactivation characteristics such membrane-bound small RNA might possess. However, we must admit the possibility that these agents are a new class of viruses without nucleic acids. The proof of this is by no means yet available (Diener, 1971a, 1971b, 1972a, 1972b, 1972c; Diener and Lawson, 1972; Diener and Raymer, 1697, 1969; Diener and Smith, 1971).

These viruses could be associated or satellite viruses which serve to activate or are themselves activated by some helper virus latent in the susceptible host (Gajdusek, 1972). The agents may be large molecules, rather than complex assemblies of macramolecular subunits. They are not restricted to nuclear fractions as are the viroids of Diener et al (1971); if they contain nucleic acid, the coding molecules may well be as small, for the neutron beam inactivation data indicate for the scrapie agent a very small target size (Alper, Haig, and Clarke, 1966; Field, Farmer, Caspary, and Joyce, 1969). At any rate, the agents possess the virus-like property of activating their own synthesis in cells which may already possess codons for the synthesis of these activating agents. Such could be an integrated complementation or a depression action which activates synthesis of more of themselves, coded for by normally repressed or 'turned-off' coding sequences. It is a semantic problem whether we call this depressing agent which transmits the disease and 'turns on' its own synthesis a virus or not. They are surely less organized into easily recognizable packages than the adeno-associated satellite agents. The numerous examples in bacteriophage genetics of transmissible 
agents which in the appropriate system activate the replication of more of themselves, as well as the replication of integrated or cytoplasmic viruses which may be incomplete, even when activated, give us many models to call upon. Thymine starvation of Bacillus subtilis stimulates the vegetative production of partial viruses called plasmids which can then be transmitted from bacillus to bacillus; other models that are called to mind are the episome model, and the integrated F-factor, and the drug resistance transfer factor of Watanabe. The term 'plasmid' has been applied to almost any bit of cytoplasmic DNA with a potential genetic future. These may act as depressors activating genetic information for the synthesis of other partial or complete viruses which may be lying in the cell as a result of past infections in earlier generations. The synthesis of the plasmid by the cell may be dependent on the depression of preexisting genetic information for other viruses and these serve as helper codons for synthesis of the plasmid. If such factors contained only 20 to 40 coding sequences, they might be very resistant to ultraviolet inactivation.

Unanswered crucial questions posed by all of these agents are related to their biological origin and mode of survival in nature. The diseases they evoke are not artificial diseases, produced by researchers tampering with cellular macromolecular structures, as some would have it. They are naturally occurring diseases, for none of which do we know the mode of dissemination or maintenance which is adequate to explain their long-term persistence. For kuru the contamination of close kinsmen within a mourning family group by the opening of the skull of the dead victims in a rite of cannibalism during which all girls and women and babes-in-arms and toddlers of the kuru victim's family were thoroughly contaminated with the virus, seems to provide a full explanation of the unique epidemiological findings in kuru and their change over the past two decades (Gajdusek, 1972). The disease is gradually disappearing with the cessation of cannibalism, and has already disappeared first from children, with progressively increasing age of the youngest victims (Figs. 1 and 2). However, this does not provide us with a satisfactory explanation for the origin of kuru. Was it the unlikely event of a sporadic case of world-wide CreutzfeldJacob disease, which in the unusual cultural setting of New Guinea produced a unique epidemic? Serial brain passage might have resulted in a change in the clinical picture of the disease with modification of the virulence of the original agent. Or was such serial brain passage as might occur through this ritual inoculation of brain from successive victims in multiple sequential passages into their kinsmen sufficient to have produced a new neurotropic strain

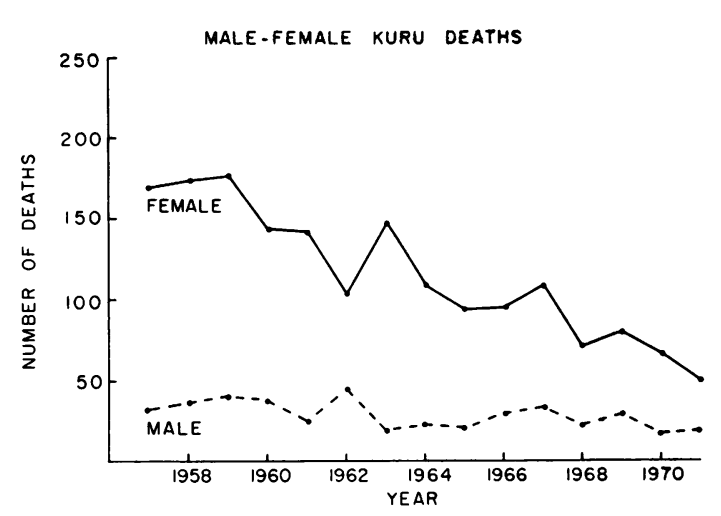

Fig. 1 Kuru deaths by sex, 1957-1971. The decline in incidence has occurred during the period of evolution from a Stone Age culture practising endocannibalistic consumption of dead kinsmen as a rite of mourning to a modern coffee-planting society practising a cash economy. This decline has followed cessation of ritual cannibalism which occurred between 1957 and 1962 in various villages.

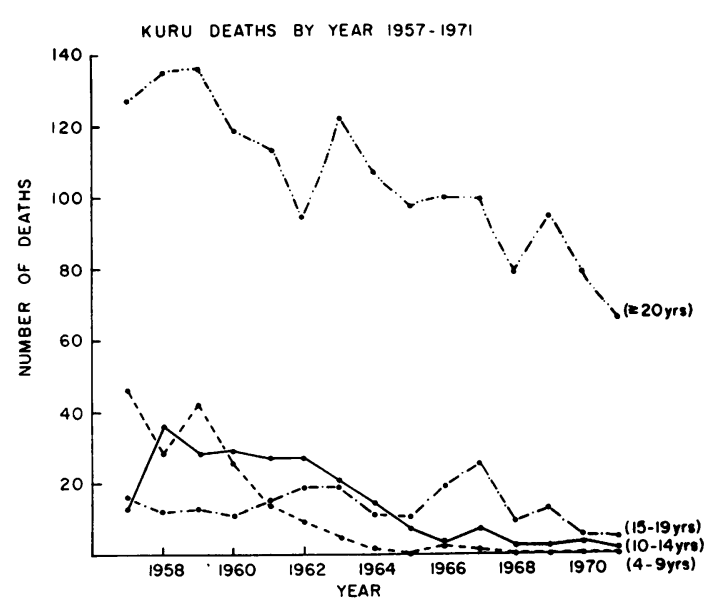

Fig. 2 Kuru deaths by age group, 1957-1971. With the cessation of ritual cannibalism, there has been a gradual disappearance of child cases of kuru (under 15 years of age). The youngest kuru victims in any recent years have come from those villages last to abandon the practice. Adolescent cases (15 to 19 years of age) are now declining, as are those in adults ( $>20$ years of age).

of virus from some well known virus? Finally, in view of what may occur in the defective repressed replication of measles virus in patients with SSPE, we must wonder whether a ubiquitous, or at least well known virus may not be modified into a defective, incomplete, or highly integrated or repressed 
agent in vivo. Such a new breed of virus may no longer be easily recognizable antigenically or structurally because of failure of full synthesis of viral subunits or of their assembly into a known virion. Thus, we may ask whether kuru does not contain some of the subunits of a known agent, modified by its unusual passage history.

\section{Genetic Determination of Slow Virus Disease Expression}

These diseases have a peculiar epidemiology which in the case of both kuru and scrapie has strongly suggested a genetic component in their determination. The behaviour of natural scrapie in Great Britain has been explained in fully genetic terms, with the expression of the disease occurring as a genetic recessive train in homozygotes only (Parry, 1966). Kuru has been similarly 'explained', and to date over 2500 cases have failed to reveal an exception which would refute the possibility that the occurrence of the disease is determined by a single gene, dominant in the adult female and only partially penetrant in the adult male, but producing an earlier appearing, more acute form of illness in children of both sexes when present in homozygous condition (Gajdusek and Alpers, 1972). With the epidemiology of kuru now easily explained by the massive contamination of infants and toddlers and themselves by girls and women who officiated at the cannibalistic dissection of the corpse for the consumption of the dead relatives as an act of mourning and respect, we had little reason to continue thinking along genetic lines(Gajdusek, 1972). Recent analysis, however, of blood group and serum protein pleomorphisms in kuru victims and normal people from the kuru region continues to suggest the possibility of genetic determination of disease expression, in spite of its obvious viral cause (Kitchen, Bearn, Alpers, and Gajdusek, 1972; Wiesenfeld, Ferber, Harpending, and Gajdusek, 1972).

All the tantalizing evidence of genetic determination of epidemiological pattern and disease in individuals is further supported by the strangely different beh aviour of the various agents of the group in different a nimal hosts. They demonstrate a marked species specificity. Thus, scrapie causes disease in most breeds of sheep, but different breeds are differently susceptible, and some are entirely resistant to the virus (Gordon, 1966; Hadlow and Eklund, personal communication). Goats are more susceptible than are any breeds of sheep, and several rodents, including rats, mice, hamsters, voles, and gerbils, are susceptible. Guinea pigs and rabbits are, however, not susceptible, nor is the cow or horse, nor chicken or any other avian host. Scrapie has failed to produce disease in the chimpanzee or New World monkeys which are susceptible to kuru and Creutzfeldt-Jakob disease after many years of waiting since these animals were inoculated intracerebrally with the virus. However, five and a half years after intracerebral inoculation of a cyanomologus monkey the animal developed experimental scrapie (Gibbs and Gajdusek, 1972). Thus even this common disease of world-wide distribution can no longer be considered innocuous for primates.

Kuru susceptibility varies markedly in different species, but a kuru-susceptible non-primate host has not yet been found. Chimpanzees are uniformly susceptible to kuru (Asher, Gibbs, Alpers, and Gajdusek, 1972; Gajdusek and Gibbs, 1972), and so are five species of New World monkey: spider, capuchin, and squirrel (Gajdusek and Gibbs, 1971), woolly and marmoset (Deinhart, Gibbs, and Gajdusek, 1972), but with longer incubation periods on primary passage. In all of these species the incubation period may fall on serial passage to considerably shorter periods than that after primary inoculation, and this virus-like 'adaptation' on passage in a new host is a reproducible phenomenon. Although no inoculated Old World monkeys have previously developed disease after inoculation with kuru brain, recently, eight and a half years after intracerebral inoculation of brain from a human kuru victim, a rhesus monkey has developed the disease (Gajdusek and Gibbs, 1972). The different behaviour of various primates is remarkable in respect to either total resistance or total susceptibility and also to marked differences in incubation periods.

Creutzfeldt-Jakob disease has shown virtually the same spectrum of susceptibility in various primates as has kuru and in this respect resembles kuru very closely indeed. In only one matter is there a real difference: the incubation period in the chimpanzee is only half as long on primary passage as is that for kuru (Gajdusek and Gibbs, 1972).

There are several families with Creutzfeldt-Jakob disease appearing over several generations in close relatives, in what appears to be a Mendelian dominant form of inheritance. Brain suspensions from a patient from one such family has caused the same transmissible disease in a chimpanzee as has such brain suspension from the sporadic form of the disease. This, of course, forces us to consider the possibility of slow virus infections underlying the pathogenesis of many subacute or chronic noninflammatory diseases which have hitherto been accepted as being 'heredofamilial' (Ferber, Wiesenfeld, Roos, Bobowick, Gibbs, and Gajdusek, 1972).

\footnotetext{
References

Adams, D. H. (1970). The nature of the scrapie agent: a review of recent progress. Path. et Biol., 18, 559-577.
} 
Alper, T. (1972). Is the agent of potato spindle tuber disease a scrapoid? Nature [new Biol.] in press.

Alper, T., Haig, D. A., and Clarke, M. C. (1966). The exceptionally small size of the scrapie agent. Biochem. biophys. Res. Commun., 22, 278-284.

Asher, D. M. (1971). Focal neurological disease with chronic encephalit is in children and in an experimental primate model. In Proceedings of the XIII International Congress of Pediatrics, Vienna, 1971, Vol. III/2, Neurology and Psychiatry, pp. 379384. Vienna Academy of Medicine.

Asher, D. M., Gibbs, C. J., Jr., Alpers, M., and Gajdusek, D. C. (1972) Experimental kuru in the chimpanzee. Physical findings and clinical laboratory studies. Adv. Primatol., in press.

Baublis, J. V., and Payne, F. E. (1968). Measles antigen and syncytium formation of brain cell cultures from subacute sclerosing panencephalitis (SSPE). Proc. Soc. exp. Biol. (N.Y.), 129, 593-597.

Beck, E., Daniel, P. M., and Gajdusek, D. C. (1966). A comparison between the neuropathological changes in kuru and scrapie, a system degeneration. In Proceedings of the 5th International Congress of Neuropathology, Zurich, 1965. (Excerpta Medica, International Congress Series No. 100), edited by F. Lüthy and A. Bischoff, pp. 213-218. Excerpta Medica Foundation, Amsterdam.

Beck, E., Daniel, P. M., Gajdusek, D. C., and Gibbs, C. J. Jr. (1969). Similarities and differences in the pattern of the pathological changes in scrapie, kuru, experimental kuru and subacute presenile polioencephalopathy. In Virus Diseases and the Nervous System, edited by C. W. M. Whitty, J. T. Hughes, and F. O. MacCallum, pp. 107-120. Blackwell, Oxford.

Beck, E., Daniel, P. M., Gajdusek, D. C., and Gibbs, C. J., Jr. (1970). Subacute degenerations of the brain transmissible to experimental animals: a neuropathological evaluation. In Proceedings of the Sixth International Congress of Neuropathology, Paris, pp. 858-873. Masson, Paris.

Caspary, E. A., and Bell, T. M. (1971). Growth potential of scrapie mouse brain in vitro. Nature (Lond.), 229, 269-270.

Deinhart, F., Gibbs, C. J., Jr., and Gajdusek, D. C. Transmission of kuru to marmosets. (In preparation).

Diener, T. O. (1971a). Potato spindle tuber virus: a plant virus with properties of a free nucleic acid. III. Subcellular location of PSTV-RNA and the question of whether virions exist in extracts or in sit 2 . Virology, 43, 75-89.

Diener, T. O. (1971b). Potato spindle tuber 'virus'. IV. A replicating, low molecular weight RNA. Virology, 45, 411-428.

Diener, T. O. (1972a). Is the scrapie agent a viroid? Nature [new Biol.], 235, 59, 218-219.

Diener, T. O. (1972b). Answer to comment by Alper, T. (1972). Nature [new Biol.], in press.

Diener, T. O. (1972c). Potato spindle tuber viroid. VIII. Correlation of infectivity with a UV-absorbing component and thermal denaturation properties of the RNA. Virology, in press.

Diener, T. O., and Lawson, R. H. (1972). Chrysanthemum stunt: a viroid disease. Virology, in press.

Diener, T. O., and Raymer, W. B. (1967). Potato spindle tuber virus: a plant virus with properties of a free nucleic acid. Science, 158, 378-381.

Diener, T. O., and Raymer, W. B. (1969). Potato spindle tuber virus: a plant virus with properties of a free nucleic acid. II. Characterization and partial purification. Virology, 37, 351-366.

Diener, T. O., and Smith, D. R. (1971). Potato spindle tuber viroid. VI. Mono-disperse distribution after electrophoresis in $20 \%$ polyacrylamide gels. Virology, 46, 498-499.

Ferber, R. A., Wiesenfeld, S. L., Roos, R., Bobowick, R., Gibbs, C. J., Jr., and Gajdusek, D. C. (1972). Familial Creutzfeldt-Jakob disease. With a report on the transmission of the familial disease to the chimpanzee. (In preparation).

Field, E. J., Farmer, F., Caspary, E. A., and Joyce, G. (1969). Susceptibility of scrapie agent to ionizing radiation. Nature (Lond.), 222, 90-91.

Gajdusek, D. C. (1972). Slow virus infections and activation of latent virus infections in aging. Advanc. geront. Res., 4, 201-218.

Gajdusek, D. C. (1972). Kuru in the New Guinea Highlands. In Tropical Neurology, edited by J. D. Spillane, Oxford University Press, London, in press.

Gajdusek, D. C., and Alpers, M. (1972). Genetic studies in relation to kuru. I. Cultural, historic and demographic background. Amer. J. hum. Genet., in press.
Gajdusek, D. C., and Gibbs, C. J., Jr. (1971). Transmission of two subacute spongiform encephalopathies of man (kuru and Creutzfeldt-Jakob disease) to New World monkeys. Nature (Lond.), 230, 588-591.

Gajdusek, D. C., and Gibbs, C. J., Jr. (1972a). Transmission of kuru from man to the rhesus monkey (Macaca mulata) $8 \frac{1}{2}$ years following inoculation. Nature (Lond.), in press.

Gajdusek, D. C., and Gibbs, C. J., Jr. (1972b). Subacute and chronic diseases caused by atypical infections with unconventional viruses in aberrant hosts. In Perspectives in Virology, in press.

Gajdusek, D. C., Gibbs, C. J., Jr., Rogers, N. G., Basnight, M., and Hooks, J. (1972). Persistence of viruses of kuru and CreutzfeldtJakob disease in tissue cultures of brain cells. Nature (Lond.), 235, 104-105.

Gardner, S. D., Field, A. M., Coleman, D. V., and Hulme, B. (1971). New human papovavirus (B.K.) isolated from urine after renal transplantation. Lancet, 1, 1253-1257.

Gibbons, R. A., and Hunter, G.D. (1967). Nature of the scrapie agent. Nature (Lond.), 215, 1041-1043.

Gibbs, C. J., Jr., and Gajdusek, D. C. (1972). Transmission of scrapie to the cynomolgus monkey (Macaca fascicularis). Nature (Lond.), 236, 73-74.

Gordon, W. S. (1966). Variation in susceptibility of sheep to scrapie and genetic implications. In Scrapie Seminar, U.S. Department of Agriculture. Publication ARS 91-53, 53-68.

Gustafson, D. P., and Kanitz, C. L. (1965). Evidence of the presence of scrapie in cell cultures of the brain. In Slow, Latent, and Temperate Virus Infections (NINDB Monograph, No. 2), edited by D. C. Gajdusek, C. J. Gibbs, Jr., and M. Alpers, pp. 221-236. Institute of Neurological Diseases and Blindness, Washington, D.C.

Hadlow, W., J. and Eklund, C. M. Personal Communication.

Haig, D. A., and Clarke, M. C. (1971). Multiplication of the scrapie agent. Nature (Lond.), 234, 106-107.

Haig, D. A., Clarke, M. C., Blum, E., and Alper, T. (1969). Further studies on the inactivation of the scrapie agent by ultraviolet light. J. gen. Virol., 5, 455-457.

Horta-Barbosa, L., Fuccillo, D. A., London, W. T., Jabbour, J. T., Zeman, W., and Sever, J. L. (1969). Isolation of measles virus from brain cell cultures of two patients with subacute sclerosing panencephalitis. Proc. Soc. exp. Biol. (N.Y.), 132, 272-277.

Hunter, G. D. (1970). The biochemical properties and nature of the scrapie agent. In Proceedings of the sixth International Congress of Neuropathology, Paris, pp. 802-817. Masson, Paris.

Kimberlin, R. H., Millson, G. C., and Hunter, G. D. (1971). An experimental examinaticn of the scrapie agent in cell membrane mixtures. III. Studies of the operational size. J. comp. Pathol. 81, 383-391.

Kitchen, F. D., Bearn, A. G., Alpers, M., and Gajdusek, D. C. (1972), Genetic studies in relation to kuru. III. The distribution of the inherited serum group specific protein $(\mathrm{Gc})$ phenotypes in New Guineans: an association of kuru and GcAb phenotypes. Amer. $J$. hum. Genet., in press.

Lampert, P. W., Earle, K. M., Gibbs, C. J., Jr., and Gajdusek, D.C (1969). Experimental kuru encephalopathy in chimpanzees and spider monkeys: electron microscopic studies. J. Neuropath. exp. Neurol., 28, 353-370.

Lampert, P. W., Earle, K. M., Gibbs, C. J., Jr., and Gajdusek, D. C. (1970). Electron microscopic studies on experimental spongiform encephalopathies (kuru and Creutzfeldt-Jakob disease) in chimpanzees. In Proceedings of the sixth International Congress of Neuropathology, Paris, pp. 916-930. Masson, Paris.

Lampert, P. W., Hooks, J., Gibbs, C. J., Jr., and Gajdusek, D. C. (1971). Altered plasma membranes in experimental scrapie. Acta neuropath. (Berl.), 19, 81-93.

Latarjet, R., Muel, B., Haig, D. A., Clarke, M. C., and Alper, T. (1970). Inactivation of the scrapie agent by near monochromatic ultraviolet light. Nature (Lond.), 227, 1341-1343.

Marsh, R. F. K., and Hanson, R. P. (1969). Transmissible mink encephalopathy: neurological response. Amer. J. vet. Res., 30 1643-1653.

Millson, G. C., Hunter, G. D., and Kimberlin, R. H. (1971). An experimental examination of the scrapie agent in cell membrane mixtures. II. The association of scrapie activity with membrane fractions. J. comp. Path., 81, 255-265.

Padgett, B. L., Walker, D. L., ZuRhein, G. M., Eckroade, R. J., and Dessel, B. H. (1971). Cultivation of papova-like virus from human brain with progressive multifocal leucoencephalopathy. Lancet, 1, 1257-1260. 
Parry, H. B. (1966). In Scrapie Seminar, U.S. Department of Agriculture Publication ARS. 91-53, 93-107, 117-135, 153-171, 300-340,

Roos, R., Chou, S. M., Rogers, N. G., Basnight, M., and Gajdusek. D. C. (1972). Isolation of an adenovirus 32 strain from human brain in a case of subacute encephalitis. Proc. Soc. exp. Biol. (N.Y.), 139, 636-640.

Wiesenfeld, S. L., Ferber, R. A., Harpending, H. C., and Gajdusek, D. C. (1972). Genetic studies in relation to kuru VI. Genetic analysis of a slow virus infection. Genetic differentiation among kuru and normal Fore. Amer. J. hum. Genet., in press.

Weiner, L. P., Herndon, R. M., Narayan, O., and Johnson, R. T. (1972a), Further studies of a simian virus 40-like virus isolated from human brain. J. Virol., 10, 147-149.

Weiner, L. P., Herndon, R. M., Narayan, O., Johnson, R. T., Shah, K., Rubinstein, L. J., Preziosi, T. J., and Conley, F. K. (1972b). Isolation of virus related to SV40 from patients with progressive multi-focal leucoencephalopathy, New Engl. J. Med., 286 385-390. 